\title{
Neuroprotective Effects of Microfluidic Encapsulated Induced Conjunctival Mesenchymal Stem Cells Through Autophagy Modulation in a Parkinsonian Model
}

Hossein Mostafavi ( $\square$ mostafavih@zums.ac.ir)

Zanjan University of Medical Sciences

Meysam Forouzandeh

Shahid Beheshti University

Mohammad Reza Bigdeli

Shahid Beheshti University

Samad Nadri

Zanjan University of Medical Sciences

Mehdi Eskandari

Zanjan University of Medical Sciences

\section{Research Article}

Keywords: Parkinson's disease, alpha-synuclein, Conjunctival MSCs, mTOR, tyrosine hydroxylase

Posted Date: November 1st, 2021

DOI: https://doi.org/10.21203/rs.3.rs-974624/v1

License: (c) (1) This work is licensed under a Creative Commons Attribution 4.0 International License.

Read Full License 


\section{Abstract}

Background and Aim: Parkinson's disease (PD) is a progressive neurodegenerative disorder in which cause is attributed to the alpha-synuclein (a-Syn) accumulation due to the decreases rated of autophagy. According to recent studies, cell therapy has been attracted much attention for PD treatment. Due to the many advantages mesenchymal stem cells (MSCs) have proposed, they have been considered a valuable resource for PD cell therapy. The present study aimed to investigate the therapeutic effect of Conjunctival MSCs (CJ-MSCs) on the autophagy manner and the expression of Mammalian target of rapamycin (mTOR), TH, and a-Syn in the parkinsonian rat model.

Materials and Methods: our investigation has been performed using the Parkinson's model of rats. Stereotaxic 6-hydroxy dopamine (6-OHDA) was injected directly into the medial forebrain bundle (MFB) to induce Parkinson's disease. An apomorphine-induced rotation test was used to confirm the model establishment. CJ-MSCs were encapsulated in alginate microgel using a microfluidic system. The green fluorescent protein (GFP) labeled CJ-MSCs both encapsulated and free cells were transplanted into the rats' right striatum. Behavioral and molecular analyses have been carried out to evaluate the potency of CJ-MSCs (both encapsulated and free cells) on PD rats. The Rotation, Rotarod Open field test was recruited as the behavioral tests. Immunohistochemistry was used to determine the tyrosine hydroxylase (TH), and Real-Time Quantitative Reverse Transcription PCR (qRT-PCR) has been performed for investigating the a-Syn and mTOR gene expression.

Results: Our obtained results indicated that transplantation of CJ-MSCs leads to a decrease in the number of rotations while raising the balance and motor abilities. Immunohistochemistry analysis revealed an increase in the number of $\mathrm{TH}^{+}$cells compared to the control group. The gene expression evaluation showed a significant reduction in MTOR and a-Syn mRNA levels than the control group. Our results also represented a significant difference between rats receiving encapsulated CJ-MSCs compared to the group received free CJ-MSCs.

Conclusion: It seems that CJ-MSCs can promote the degradation of intracellular a-Syn by reducing mTOR and thus increase TH expression that led improve the motor functions of rats. Our results indicated the CJ-MSCs as a suitable source of MSCs to reduce PD complications.

\section{Introduction}

Parkinson's disease (PD) is the second most common neurodegenerative disorder after Alzheimer's disease; however, it is the most agile cause of neurological disability. PD is characterized both by motor and non-motor complications. Tremor, stiffness, bradykinesia, gait, and balance disorders are attributed to motor complications, while cognitive, behavioral, emotional, sleep, and autonomic problems are ascribed to as non-motor problems (Obeso et al., 2017). Despite current therapeutic approaches, including dopaminergic and other pharmacological and surgical therapies, PD is still progressive. 
Therefore, identifying disease-modifying treatments seems to be required (Fox et al., 2018, Jankovic., 2019).

Alpha-Synuclein (a-Syn) is a 140-amino acids protein that binds to the membranes of synaptic vesicles. This protein does not turn into fibrils in the normal condition due to highly ordered and insoluble compounds, representing a dynamic equilibrium between soluble and membrane-anchored states (Bridi and Hirth., 2018). Following induction of PD by 6-Hydroxydopamine, the a-Syn level increased and this increase is effective in the expansion of PD complications (Ganapathy et al., 2016). In case of damage to lysosomal systems and ubiquitin-proteasome, fibril and Lewy body forms are observed (Wu et al., 2009). Although various mechanism led to the dopaminergic neurons' degeneration following PD, including oxidative stress, mitochondrial dysfunction, inflammation, and apoptosis that occur in the dense part of the substantia nigra; but the accumulation of misfolded a-Syn may be addressed as the most critical cause of cellular toxicity in PD pathology that finally led to the cell apoptosis (Obeso et al., 2017). It has been recognized that malfunction of the natural destructive process, such as autophagy, may lead to the accumulation of toxic proteins (Klein and Mazzulli et al., 2018). Autophagy is defined as a cellular pathway involved in the destruction of damaged organelles and aggregated portions-the accumulation and expansion of misfolded a-Syn following impaired autophagy cause more stable cytotoxicity. Hence, increasing autophagy may be pursued as a potential and attractive therapeutic approach to reduce PD complications by intracellular degradation of a-Syn (Scrivo et al., 2018).

Mammalian target of rapamycin (mTOR) signaling has indicated to be involved in autophagy and apoptosis process regulating besides its essential role in cell development and tissue repair apoptosis (Maiese et al., 2013). Previous studies have revealed that mTOR inhibition through some medication, including s Rapamycin could upregulate the autophagy process in neurons (Sardi et al., 2018). Animal studies had shown that this process finally leads to protects dopaminergic neurons against MMP + induced cell death in a mouse model of PD and raise the autophagy rate in the $\mathrm{C}$. elegans model (Ghosh et al., 2016).

The use of stem cell-based therapies as an effective and efficient treatment for PD has attracted much attention recently. Various stem cell sources such as induced pluripotent stem cells (iPSCs), neuronal stem cells (NSCs), and embryonic stem cells (ESCs) are provided to restore neuronal function in PD (Shall et al., 2018, Barrow., 2015, Zhang et al., 2018). However, the use of ESC and NSC have shown numerous physiological problems including teratoma formation, moral limitations, histocompatibility, low efficiency of differentiation, lineage polarization, and inability to migrate to damaged areas of the brain. (Messripour and Ali-Babaie., 1994, Barker et al., 2016 Marei et al., 2018, Messripoura et al., 2018). The most significant limitations for cell transplantation are poor survival and vulnerability to neurodegeneration after transplantation attributed to the presence of neurotoxic factors and deficiency of trophic factors in the brain with PD (Marei et al., 2018).

Mesenchymal stem cells (MSCs) are pluripotent cells reported to differentiate into dopaminergic neurons after transfer to the brain with PD. MSCs presented their therapeutic effects through anti-inflammatory, 
immune modulation, cytokine secretion properties, and malfunction neurotrophic in the brain with PD (Schwerk et al., 2015). Besides, MSCs can migrate to damaged DA neurons, enabling them to act as a targeted treatment to deliver effective factors in reducing PD complications (Wang et al., 2013, DiBenedetto et al., 2017). Researchers have isolated a group of MSCs from the conjunctival epithelial cells (Wei et al., 1993, Harun et al., 2013) that express dopamine-related genes with the potency to differentiate into dopaminergic lines. Besides, the high proliferation rate and long-term culture have turned them into a potential source for cell therapy (Nadri et al., 2008a). Despite all the advantages MSCs therapy presented, the difficulty of controlling the transplanted cells' fate and the use of immunosuppressive drugs to achieve maximum cell viability with the promotion of the remaining cells against the immune system are mentioned as the major challenges. Cell immobilization through biomaterials has been proposed as a practical approach to overcoming these problems. Biomaterial-based microcapsule is an excellent method that provides a three-dimensional extracellular environment that enables easy control of cell migration, differentiation, and cellular parameters (Tan and Takeuchi et al., 2007, Yao et al., 2012, Bozza et al., 2014).

As it was mentioned, the autophagy process is disrupted, and a-SYn accumulation leads to damage to dopaminergic neurons during PD pathology. In a previous study, we showed that induced CJ-MSCs were more effective than non-induced CJ-MSCs in reducing Parkinson's complications, but the exact mechanism of this effect was not investigated (Forouzandeh et al., 2021). To the best of our knowledge, there is no study regarding the evaluation of the effect of encapsulated and inductive CJ-MSCs on the autophagy process in the brain with PD. Hence, the present study aimed to investigate the potency of the encapsulated CJ-MSCs, both inductive and non-inductive, on the mTOR signaling, a-SYn expression, and the motor effects of PD induction in rats.

\section{Materials And Methods}

\section{2-1- Animal model}

In the present study, male Wistar rats weighing 220-270 g were used as the animal model for further investigation. The animals were kept under normal humidity, temperature, and light condition (12h lightdark cycle) for a week with the ad libitum available of water and food. The animal study was accommodated with the ethical committee for using laboratory animals at Zanjan university of medical sciences, Iran.

To establish PD models, briefly, the rats were anesthetized using ketamine and xylazine with the concentration of 100 and $10 \mathrm{mg} / \mathrm{kg}$, respectively, and subsequently were fixed in a stereotaxic device (Stoelting, USA). A razor blade has been used to carve the rats' skull to determine the medial forebrain bundle (MFB) coordinates recruiting the Paxinos and Watson Atlas as AP: $-4 \mathrm{~mm}$ bregma, ML: $1.8 \mathrm{~mm}$ from the midline, DV: $8.8 \mathrm{~mm}$ from the skull. A dental drill and a Hamilton syringe have employed to establish a small hole in the skull bone and the injection of 6-OHDA $(8 \mu \mathrm{g} / 2 \mu \mathrm{l}$ normal saline containing $0.01 \%$ ascorbic acid, $\mathrm{pH}=5$ ) into the area destroying the negro-striatal pathway, respectively (Figure $1 \mathrm{~A}$ ). 
6-Hydroxydopamine can enter the dopaminergic nerve's terminal through a dopamine transporter. The mechanism in which PD is developed in animals is attributed to free radicals' production following the oxidization of injected 6-Hydroxydopamine. This phenomenon leads to dopaminergic neuronal death over interrupting mitochondrial function and oxidative stress (Reza et al., 2019). Five groups of animals each containing 8 Wistar rats were investigated in the present study as follows: (1) the sham group: healthy rats that received only surgical stress; (2) control group (PD Model): rats with Parkinson, that received no treatment; (3) vehicle group: rats with Parkinson, that treated with cell-free medium transplant in the right striatum; (4) iCJ-MSCs group: rats with Parkinson, that treated with induced CJ-MSCs $(30 \times 103$ cells per $3 \mu$ in the right striatum); (5) the microfluidic encapsulated iCJ-MSCs group: rats with Parkinson, that treated with encapsulated induced CJ-MSCs (30×103 cells per $3 \mu \mathrm{l}$ in the right striatum) (Figure 1B).

\section{2-2-Stem Cell Isolation and Characterization}

In the present study, a modified protocol has been recruited to isolate CJ-MSCs developed by Nadri et al. (Nadri et al., 2008b). Firstly, the CJ biopsy was treated with BSA and collagenase at the concentration of 40 and $4 \mathrm{mg} / \mathrm{ml}$, respectively, followed by one-hour incubation in PBS (GIBCO-BRL, Grand Island, NY). The cell mixture was cultured in low glucose DMEM (GIBCO-BRL, Grand Island, NY) supplemented with $20 \%$ serum (GIBCO-BRL, Grand Island, NY) and 200 ng/ml basic-FGF (Peprotech, Rocky Hill, NJ) and incubated in a humidified chamber at $37^{\circ} \mathrm{C}$ with $5 \% \mathrm{CO} 2$ for 14 days. At the final step, the cells were trypsinized (GIBCO) and expanded by two passages. In a previous study the pluripotent potency of isolated stem cells were carried out through culture in different medium including osteogenic using (DMEM including $50 \mathrm{mg} / \mathrm{mL}$ ascorbic acid 2-phosphate (Sigma Chemical Co. St Louis, MO), $10 \mathrm{nM}$ dexamethasone (Sigma Chemical Co.), 10 mM b-glycerophosphate (Sigma Chemical Co.); adipogenic using (DMEM supplemented with $50 \mathrm{mg} / \mathrm{mL}$ indomethacin (Sigma Chemical Co) and $100 \mathrm{nM}$ dexamethasone (Sigma Chemical Co); chondrogenic using (DMEM supplemented with $10 \mathrm{ng} / \mathrm{mL}$ transforming growth factor- $\beta 3$ (TGF- $\beta 3$, Sigma Chemical Co), bone morphogenetic protein-6 (BMP-6), 10 -7M dexamethasone (Sigma Chemical Co.), $50 \mathrm{mg} / \mathrm{mL}$ ascorbate- 2-phosphate (Sigma ChemicalCo.), and $50 \mathrm{mg} / \mathrm{mL}$ insulintransferring-selenium (ITS, GIBCO-BRL) for 21 days (Nadri et al., 2008b).

\section{2-3- Transduction and GFP Labeling of CJ-MSCs}

Toward GFP transduction to the isolated CJ-MSCs, a lentivirus enriched medium was added to the complete media followed by decanted to the cultured CJ-MSCs. Medium changing was performed after 24 hours. Puromycin antibiotic $(2 \mathrm{mg} / \mathrm{mL})$ was used to separate GFP labeled CJ-MSCs and expanded for 3-5 days in high glucose DMEM containing 10\% FBS. GFP-labeled cells were detected using fluorescent microscopy. A neurogenic medium containing low glucose DMEM supplemented with 10 $\mu \mathrm{M}$ retinoic acid

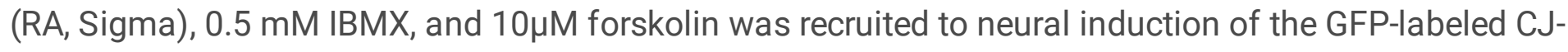
MSCs(Forouzandeh et al., 2021).

\section{2-5- Microencapsulation of CJ-MSCs}


The soft lithography method has been used to fabricate microfluidic chip according to the (Forouzandeh et al., 2021). A su8-50 sensitive polymer was coated by the rotation speed of $3000 \mathrm{rpm}$ on the silica-wafer as a solid phase for 5 minutes and was soft baked on a hot plate $\left(65^{\circ} \mathrm{C}\right.$ for 5 minutes and $95^{\circ} \mathrm{C}$ for 30 minutes). The ultraviolet light with the wavelength of 330-430 nm was radiated to the coated silica-wafer in the next step. A developer solution was used to wafer immersion after soft baking followed by nitrogen gas drying. To fabricate PDMS channels, a 1:10 w/w mixture of the crosslinker and Sylgard 184 (Dow Corning Corporation) was prepared and poured onto the fabricated masters. PDMS channels were formed through SU-8 and suitable holes were embedded to connect microtubes.

Sodium alginate (Sigma, A2033) and calcium chloride ( $\mathrm{CaCl} 2$, Merck, Germany) were used as the encapsulation and crosslinker materials, respectively. A total number of $30 \times 103$ of passage- 6 CJ-MSCs, were cultured in DMEM medium containing $1.5 \% \mathrm{w} / \mathrm{v}$, sodium alginate in non-adherent culture dishes. As shown in (Supplementary Figure 1), the alginate containing cells and $40 \mathrm{nM} \mathrm{CaCl} 2$ solutions were introduced to the two different inlets of the microfluidic chip (Supplementary Figure 2). The suitable flow rates for each solution were calculated based on the output microgel rigidity. Harvested microgel was incubated in a plate containing $100 \mathrm{nM} \mathrm{CaCl} 2$ solution for 10 minutes to promote consistency. Finally, the appropriate encapsulated CJ-MSCs in alginate microgel were washed with PBS (Forouzandeh et al., 2021).

\section{2-6- Cell Transplantation}

Due to various advantages stereotaxic method provided for cell transplantation including, short operation time and small surgery for local transplantation, which led to local anesthesia and concentrated transplanted cells to the desired area, CJ-MSCs were transplanted using this method. All rats were anesthetized with ketamine $(100 \mathrm{mg} / \mathrm{kg})$ and xylazine $(10 \mathrm{mg} / \mathrm{kg})$ and fixed in a stereotaxic device (Stoelting, USA). Free and encapsulated CJ-MSCs at the total number of $30 \times 103 / \mathrm{ml}$ were transplanted through a Hamilton syringe into the rats' right striatum. Paxinos atlas was used to determine the right striatum area in which AP, $1.2 \mathrm{~mm}$ from the bregma, $\mathrm{ML},+3 \mathrm{~mm}$ from the midline, DV $6 \mathrm{~mm}$ from the skull (Forouzandeh et al., 2021)..

\section{2-7- Rotation Test}

In the present study, intraperitoneal injection of apomorphine at the concentration of $0.5 \mathrm{mg} / \mathrm{kg}$ was used to perform a rotation test. This test's underlying mechanism is based on the dopamine receptors response of affected substantia nigra in animals to dopamine and dopamine agonists such as apomorphine. After apomorphine injection to the lesions, animals begin to rotate in the opposite direction. The total number of rotations is attributed to the intensity of the lesion. To perform the rotation test, rats were firstly adapted to the rotameter (Borj Sanat azma RT-5300 Tehran, Iran) for 5 minutes. Next, the number of rotations to the opposite side of the lesion (left) was calculated for all rats using the rotameter following intraperitoneal injection of $1 \mathrm{mg} / \mathrm{kg}$ of the apomorphine hydrochloride. We have conducted this test on day 0 (two weeks after Parkinson's induction and just before cell transplantation), 14 (two weeks after cell transplantation), 28 (four weeks after cell transplantation), and 42 (eight weeks 
after cell transplantation) (Figure 1B) (Mostafavi et al., 2019). Data were expressed in the form of a complete body rotation every minute as the following equation:

Output rotations= Rotations in the lesion direction - rotations in the opposite direction of the lesion

\section{2-8-Rotarod Test}

To investigate motor coordination, the Rotarod device (Stoelting USA) have used to perform the rotarod test on days 0,28 , and 42 (Figure 1B). Before the test, the animals were exercised for two days through $4 \mathrm{rpm}$ and $15 \mathrm{rpm}$ for the first and second days, respectively. To evaluate rats' coordination, the rotation speed of the device increased from $4 \mathrm{rpm}$ to $40 \mathrm{rpm}$ in $180 \mathrm{~s}$. The rats' balanced time to stay on the rotating rod was recorded with an interval of 5 minutes. The device would automatically start recording time $0.1 \mathrm{~s}$ after the rat was placed on the rotating rod (Forouzandeh et al., 2021). All tests were recorded in triplicate.

\section{2-9- Open Field Test}

The cognitive activities improvement of the rats was evaluated through an open field test after treatment. After adoption, inducted animals were placed in the center of the open field device (OPF, insight model open field EP 154C, Borj Sanat Azma RT-5300, Tehran Iran) for 5 minutes to record their activity. The movement frequency and the rearing frequency were evaluated as the required parameters (Forouzandeh et al., 2021).

\section{2-10- RT-qPCR}

The expression of a-Syn and mTOR mRNA were assessed through Quantitative Real-Time PCR (RTqPCR). Briefly, total RNA was extracted using Trizol followed by quality and quantity determination using nanodrop (Themo Fisher, 2000). According to the manufacturer's instructions, mRNA cDNA Synthesis Kit (Stem Cell Technology Research Center BON209002) has been recruited for CDNA synthesis. Syber green master mix (Amplicon) has been employed to evaluate the gene expression using specific primers (Table 1) by RT-qPCR device (Applied bioscience).

\section{2-11- Immunohistochemistry analysis}

Immunohistochemistry analysis was used through Tyrosine hydroxylase (TH) staining after the behavioral tests. A solution of Ketamine/xylazine with the ratio of $100 / 10 \mathrm{mg} / \mathrm{kg}$ was injected intraparietal to deeply anesthetize the rats. A volume of $250 \mathrm{ml}$ sodium chloride $0.9 \%$ was used to transcardial perfusion, followed by $100 \mathrm{ml}$ formaldehyde $4 \%$ to remove the brain, and fixed in formalin $4 \%$ and embedded in paraffin. Thin sections of brains were prepared and deparaffinized using xylene followed by dehydration in a serial dilution of ethanol ( $100 \%, 96 \%$, and $70 \%$ ethanol). After $0.5 \%$ Triton X100 treatment for 10 minutes, the sections were incubated for 12 hours at four ${ }^{\circ} \mathrm{C}$ with primary antibodies for $\mathrm{TH}$. Then the sections were incubated another 1 hour with the PE-conjugated IgG as a secondary antibody at room temperature. In order to diaminobenzidine (DAB) staining, the sections were incubated 
with the DAB solution for 10 seconds at room temperature. A fluorescence microscope (Olympus, Japan) was used to visualize and analyzed the sections.

\section{2-12-Statistical analysis}

All statistics were reported as mean \pm SD. One-Way ANOVA and Tukey post hoc test with the significance threshold of $p<0.05$ was used to analyzing data.

\section{Results}

\section{3-1- CJ-MSCs isolation and GFP-transduction}

In a previous study the isolated conjunctival stem cells were cultured in osteogenic, adipogenic, and chondrogenic mediums to confirm the mesenchymal nature. The differentiation potency has been evaluated through alizarin red, oil red, and alcian blue staining. The presence of extracellular calcium, redcolored fat vacuoles, and the purple color has been observed that implied stem cells differentiated into the osteogenic, adipogenic, and chondrogenic lineages, respectively (Nadri et al., 2008b). Microscopic observation of the GFP-transduced CJ-MSCs has been shown a green color a week after transduction. As shown in Figure 2, the cells demonstrated a nerve-like cell morphology due to exposure to the nerve induction medium.

\section{3-2-CJ-MSCs encapsulation}

A microfluidic system (Supplementary Figure 2) with two inlets for sodium alginate containing CJ-MSCs and $\mathrm{CaCl} 2$ has been used to encapsulate CJ-MSCs. The channel diameter of the fabricated microchip was $300-600 \mu \mathrm{m}$ in which the microgel was formed during the channels and extracted from the outlet to the dishes containing $100 \mathrm{nM} \mathrm{CaCl}_{2}$ (Supplementary Figure 1). The flow rate of 1.5 and $3 \mathrm{ml} / \mathrm{hr}$ has been used to introduce $1.5 \% \mathrm{w} / \mathrm{v}$ sodium alginate and a $40 \mathrm{nM} \mathrm{CaCl}_{2} \mathrm{crosslinker}$. Figure 2 shows the experimental procedure of the CJ-MSCs encapsulation.

\section{3-3- Decreased rotation number induced by apomorphine following CJ-MSCs transplantation:}

The obtained rotation test data have been shown that PD induction leads to apomorphine-induced rotations to the opposite side of the lesion (left) in rats (Figure 3A). Encapsulated and non-encapsulatedCJ-MSCs transplanted rats have represented a significant reduction of the number of rotations compared to the PD model group after 14 days (Figure 3B). Encapsulated- CJ-MSCs transplanted rats have also been shown more decreased rotation number compare to non-encapsulated-CJ-MSCs transplanted rats (Figure 3B-D). The number of rotations for the cell-treated groups showed a significant decrease on days 14,28 , and 42 compared to day 0 . A significant difference was indicated for cell recipient groups on day 42 compared to 14 and 28 and day 28 compared to day 14 were regarding the number of rotations (Figure 3E).

\section{3-4- Balance improvement in rats following CJ-MSCs transplantation:}


According to the results, 6-OHDA injection leads to a decrease in the balance of animals in the PD model group compared to the sham group. Encapsulated-CJ-MSCs and non-capsulated CJ-MSCs have been significantly increased the remaining time of rats on the rotating rod than the PD group (Figure 4A). Improvement balance in the animal has also been observed on 28 and 42 days after transplantation (Figure 4B and C). Besides, a significant difference was observed between the keeping balance of the treated groups on 28 and 42 days (Figure 4D).

\section{3-5- Improved motor skills following CJ-MSCs transplantation:}

Our investigations regarding the treated rats' movement ability revealed that PD induction has reduced the total distance (Figure 5A) and mean velocity (Figure 5B). of the rats than the sham group. However, both encapsulated and non-encapsulated CJ-MSCs transplanted PD rats have shown a significant increase in the total distance and the mean movement velocity relative to the PD model, in which encapsulated-CJ-MSCs transplanted rats showed more improvement compared to the non-encapsulated CJ-MSCs transplanted rats (Figure $5 \mathrm{~A}$ and $\mathrm{B}$ ).

\section{3-6- Decreased mTOR and a-Syn levels in the CJ-MSCs treated rats striatum:}

The results of RT-PCR showed that the a-Syn (Figure 6A) and mTOR (Figure 6B) mRNA levels had increased significantly following PD induction. Although Encapsulated and non-encapsulated CJ-MSCs transplantation led to reduced considerably mTOR and a-Syn mRNA levels compared to the PD model, encapsulated-CJ-MSCs showed to be more effective (Figure 6A and B).

\section{3-7- $\mathrm{TH}^{+}$cell number increase following $\mathrm{CJ}-\mathrm{MSC}$ transplantation:}

According to Immunohistochemistry analysis, the striatum of the PD induction rats significantly reduced the number of $\mathrm{TH}+$ cells compared to the sham group. While encapsulated and non-encapsulated $\mathrm{CJ}$ MSCs transplantation led to increased TH expression compared to the PD model group. It has been shown that encapsulated CJ-MSCs transplanted rats expressed more TH compared to the noncapsulated CJ-MSCs (Figure 7A and B).

\section{Discussion}

Despite the rapidly growing stem cell use for PD therapy, it encountered some challenges. Ethical concerns can be mentioned as an obstacle to embryonic stem cells' use (Venkatesh and Sen., 2017, Danisovic et al., 2017). However, due to unique properties such as the ability to differentiate into dopaminergic neurons and stimulate the differentiation of host stem cells, MSCs shared a higher potential to prevent oxidative stress and neuronal death than other cells (Teixeira et al., 2013, Vizoso et al., 2017). Due to invasive methods and low isolated stem cells from bone marrow, appropriate sources of MSCs are also needed (Astori et al., 2007, Blaber et al., 2012). CJ-MSCs have been recently isolated from the conjunctival cells that can be used for PD treatment because of the ability to differentiate into dopaminergic cells. 
It was reported that a-Syn, as the main constituent of LBs, is involved in regulating dopamine levels associated with dopamine deficiency in PD. a-Syn leads to dopamine reduction through interaction with TH (Perez et al., 2002). a-Syn can bind to the TH gene promoter and decrease its expression, resulting in a decrease in TH level (Gao et al., 2007). The accumulation of a-Syn has proven to be harmful to dopaminergic neurons. The toxic a-Syn may be transmitted from damaged cells to other adjacent cells, leading to the formation of LBs and disrupting the dopaminergic cells (Luk et al., 2012). The mRNA level of a-Syn and the number of $\mathrm{TH}+$ cells were increased and decreased, respectively, in the present study following PD induction in rats. Both encapsulated and free CJ-MSCs showed a reduced level of a-Syn and increased the number the TH + cells. It can be concluded that decreasing the a-Syn gene's level led to increased TH expression in the striatum PD rats.

According to previous studies, the mTOR signaling has been increased during PD (Bockaert and Marin., 2015, Dijkstra et al., 2015). On the other hand, various evidence implied the inhibition of mTOR signaling by Rapamycin and its derivatives, leading to neuroprotective effects on cellular and animal models of PD (Malagelada et al., 2010, Cullen et al., 2011, Jiang et al., 2013, Decressac et al., 2013). Interestingly, levodopa, the commonly used drug, causes motor side effects (dyskinesia) through activating mTOR signaling in the mouse striatum. The use of Rapamycin or its derivatives prevents the spread of levodopa-induced dyskinesia without exerting the anti-akinetic effect of levodopa on animal models (Santini et al., 2009, Subramaniam et al., 2012, Decressac et al., 2013). The primary process in which the accumulated cytoplasmic compounds such as a-Syn and defective organelles are removed is known as autophagy (Menzies et al., 2015, Nakka et al., 2016). It has been shown that inhibiting mTOR signaling can upregulate autophagy (Wang et al., 2012).

Ebrahim et al. have shown that MSC-derived exosomes can upregulate autophagy by suppressing the mTOR pathway and their antifibrotic effect (Ebrahim et al., 2018). In a similar study, MSC-derived exosomes were found to induce autophagy through AMPK/mTOR and Akt /mTOR, leading to a significant reduction in apoptosis and the volume of tissue damage (Liu et al., 2017). It has been shown that umbilical cord MSC-derived exosomes applied the same effect, in which the autophagy was increased with the decreases in apoptosis through the AMPK / mTOR pathway (Gu et al., 2020). Another study revealed that the co-culture of MSCs with MMP + treated neurons (active metabolites of the MPTP toxin) could reduce a-Syn protein expression and increase autophagy. It has been well understood that MSCs- transplantation in PD mice leads to increased formation of autophagolysosomes with a significant decrease in a-Syn expression in dopaminergic neurons, indicating that MSCs can promote the survival of dopaminergic neurons (Park et al., 2014). The present study showed that transplantation of CJ-MSCs leads to a decrease in a-Syn gene-level simultaneously with reduced mTOR gene levels. Since mTOR inhibition by increasing the autophagy process leads to degradation of a-Syn accumulated within dopaminergic cells, we suppose that CJ-MSCs have been improved the PD complications by inhibiting mTOR signaling and increasing a-Syn degradation.

Studies have shown that cell encapsulation with microfluidic systems leads to neuronal proliferation and differentiation and increases viability (Raza et al., 2019). Alginate polymer is more favorable for cell 
encapsulation due to its biological simplicity and the provision of mild gelling conditions (Lee and Mooney., 2012), leading to longer viability and maintenance of stem cell growth and division. (Hashemi et al., 2016). Regarding the dopaminergic cells, it has been shown that cell encapsulation could vigorously promote cell survival, significantly increase TH level, and improve animal behavioral and motor functions (Moriarty et al., 2017). In another study, cell survival was found to be increased up to 3.5 -fold following the use of microencapsulation, and after transplantation of target cells into the striatum, TH levels increased, and motor function improved (Adill and Vazin., 2017). Here at the present study, encapsulatedCJ-MSCs have been applied more effective results regarding motor function, a-Syn, mTOR, and TH level than the free CJ-MSCs in PD inductive rats.

According to our findings, it has been suggested that CJ-MSCs may increase the degradation of accumulated a-Syn within dopaminergic cells by decreasing mTOR activity through increasing autophagy. Thus, the TH expression has risen, and PD-induced motor complications have improved. Besides, cell encapsulation leads to the neuroprotective effect enhancement. Therefore, it may be possible to suggest CJ-MSCs as a source with therapeutic potential for PD and to encapsulate it as a mechanism to increase the neuroprotective effects.

\section{Abbreviations}

PD., Parkinson's disease, a-Syn., alpha-synuclein, mTOR., Mammalian target of rapamycin, MSCs., Mesenchymal Stem Cells, CJ-MSCs., Conjunctival Mesenchymal Stem Cells, iCJ-MSCs., induced Conjunctival Mesenchymal Stem Cells, 6-OHDA., 6-hydroxypopamine, MFB., Medial Forebrain Bundle, GFP., Green Fluorescent Protein, qRT-PCR., Real-Time Quantitative Reverse Transcription PCR, TH., Tyrosine Hydroxylase, iPSCs., induced pluripotent stem cells, mesDA., NSCs., neuronal stem cells, Mesenchymal Dopaminergic Neurons, ESCs., Embryonic stem cells,

\section{Declarations}

\section{5- Acknowledgments}

The results presented in this article were extracted from Ph.D thesis of Meysam forouzandeh (90-10-92240). We thank the Research Deputy of Zanjan University of Medical Sciences for support of this project.

\section{Funding source}

None

\section{Declarations of interest}

None.

\section{Availability of data}


The analyzed data of this study will be made available by the corresponding author upon reasonable request.

\section{Ethics approval}

The animals were tested according to the guidelines of the International Organization for Medical Science Working with Laboratory Animals. The protocol for working with animals was approved by the ethics committee of Zanjan University of Medical Sciences.

\section{Consent to participate:}

Not applicable

\section{Consent for publication}

Not applicable

\section{Competing interests}

The author declares that they have no competing interests.

\section{Author contributions:}

Meysam Forouzandeh: Methodology, Writing- Original draft preparation and Editing.

Mohammad Reza Bigdeli: Conceptualization, Methodology, Software, Validation, Writing- Reviewing, Resources, Supervision

Hossein Mostafavi: Conceptualization, Methodology, Data curation, Software, Validation, WritingReviewing, Investigation, Project administration

Samad Nadri: Conceptualization, Methodology, Data curation, Software, Validation, Writing- Reviewing.

Mehdi Eskandari: Software, Validation

\section{References}

1. Adill MM, Vazin T, Ananthanaryana B, Rodrigues GMC, Rao AT, Kulkarni RU, Miller EW, Kumar S, Schaffer DV (2014) Engineered hydrogels increase the post-transplantation survival of encapsulated hESC-derived midbrain dopaminergic neurons. Biomaterials. 2017; 136, 1-11.

doi.org/10.1016/j.biomaterials.2017.05.008

2. Astori G, Vignati F, Bardelli S, Tubio M, Gola M, Albertini V, Bambi F, Scali G, Castelli D, Rasini, v,Soldati, G, Moccetti T (2007) "In vitro"and multicolor phenotypic characterization of cell subpopulations identified in fresh human adipose tissue stromal vascular fraction and in the derived mesenchymal stem cells. J Transl Med 5,Artivle nimber:55. doi.org/10.1186/1479-5876-5-55 
3. Barati G, Nadri S, Hajian R, Rahmani A, Mostafavi H, Mortazavi Y, Taromchi AH (2019) Differentiation of microfluidic-encapsulated trabecular meshwork mesenchymal stem cells into insulin producing cells and their impact on diabetic rats. J Cell Physiol 2019; 234(5), 6801-09. doi.org/10.1002/jcp. 27426

4. Barker RA, Parmar M, Kirkeby A, Björklund A, Thompson L, Brundin P (2016) Are stem cell-based therapies for Parkinson's disease ready for the clinic in 2016? J Parkinsons Dis 6(1):57-63. doi.org/10.3233/JPD-160798

5. Barrow TR (2015) Cell replacement therapy in Parkinson's disease. Biosci Horizons 8:hsv002. doi.org/10.1093/biohorizons/hzv002

6. Blaber SP, Vebster RA, Hill CJ, Breen EJ, Kuah D, Vesey G, Herbert BR (2012) Analysis of in vitro secretion profiles from adipose-derived cell populations. J Transl Med 0,Article number:172. doi.org/10.1186/1479-5876-10-172

7. Bockaert J, Marin P (2015) mTOR in brain physiology and pathologies.Physiological Reviews 95(4): 1157-87. doi.org/10.1152/physrev.00038.2014

8. Bozza A, Coates EE, Incitti T, Ferlin KM, Messina A, Menna E, Bozzi Y, Fisher JP, Casarosa S (2014) Neural differentiation of pluripotent cells in 3D alginate-based cultures. Biomaterials 35(16):46364645. 10.1016/j.biomaterials.2014.02.039

9. Bridi JC, Hirth F (2018) Mechanisms of a-synuclein induced synaptopathy in Parkinson's disease. Front Neurosci 12:80. doi.org/10.3389/fnins.2018.00080

10. Cullen V, Sardi SP, Ng J, Xu UH, Tomlinson JJ, Kahn P, Saftig I, Woulfe P, Rochet J, Glicksman JC, Cheng MA, Grabowski SH, Shihabuddin GA, Schlossmacher LS MG (2011) Acidb-glucosidase mutants linked to Gaucher disease, Parkinson disease, and Lewy body dementia altera-synuclein processing. Ann Neurol 69(6):940-953

11. Danisovic L, Oravcova L, Krajciova L, Varchulova-Novakova Z, Bohac M, Varga A, Vojtassak J (2017) Effect of long-term culture on the biological and morphological characteristics of human adipose tissue-derived stem cells. Physiol Pharmacol 68(1):149-158

12. Decressac M, Mattsson B, Weikop P, Lundblad M, Jakobsson J, Bjorklund A (2013) TFEB-mediated autophagy rescues midbrain dopamine neurons froma-synuclein toxicity.Proc Natl Acad Sci USA 110(19), E1817-E1826.doi.org/ 10.1073/pnas.1305623110

13. Di-Benedetto A, Posa F, Carbone C, Cantore S, Brunetti G, Centonze M, Grano M, Muzio LL, CavalcantiAdam EA, Mori G (2017) NURR1 downregulation favors osteoblastic differentiation of MSCs. Stem Cells Int 2017, 6975251. doi.org/10.1155/2017/7617048

14. Dijkstra A, Ingrassia A, Menezes RX, Kesteren RE, Rozemuller AJM, Heutink P, WD (2015) Evidence for immune response, axonal dysfunction and reduced endocytosis in the substantia nigra in early stage Parkinson's disease.PLoS ONE 2015;10(6): e0128651, e0128651

. doi.org/10.1371/journal.pone.0128651 
15. Ebrahim N, Ahmad IA, Hussein NI, Dessoukey AA, Farid AS, Elshazly AM, Mostafa WBE, Gazzar SM, Sorour Y, Seleem AM, Hussein D (2018) Mesenchymal Stem Cell-Derived Exosomes Ameliorated Diabetic Nephropathy by Autophagy Induction through the mTOR Signaling Pathway. Cells 7(12):125. doi.org/10.3390/cells 7120226

16. Forouzandeh M, Bigdeli MR, Mostafavi H, Nadri S, Eskandari M (2021) Therapeutic potentials of human microfluidic encapsulated conjunctival mesenchymal stem cells on the rat model of Parkinson's disease. Exp Mol Pathol 123;104723 doi.org/10.1016/j.yexmp.2021.104703

17. Fox SH, Katzenschlager R, Lim S-Y, Barton B, de Bie RMA, Seppi K, Coelho CSM, Coelho M, Sampaio $C$ (2018) International Parkinson and movement disorder society evidence-based medicine review: update on treatments for the motor symptoms of Parkinson's disease. Mov Disord 33(8):1248-1266. doi.org/10.1002/mds. 27372

18. Ganapathy K, Datta I, Sowmithra S, Joshi P (2016) Influence of 6-Hydroxydopamin Toxicity on aSynuclein Phosphorylation, Resting Vesicle Expression, and Vesicular Dopamine Release. Cellular Biothec 9999:1-18

19. Gao N, Li YH, Li X, Yu S, Fu GL, Chen B (2007) Effect of alphasynuclein on the promoter activity of tyrosine hydroxylase gene. Neurosci Bulletin 23(1):53-57

20. Ghosh A, Tyson T, George S, Hildebrandt EN, Steiner JA, Madaj Z, Schulz E, Machiela E, McDonald WG, Galvis MLE, Kordower JH, Raamsdonk JMV, Colca JR, Brundin P (2016) Mitochondrial pyruvate carrier regulates autophagy, infammation, and neurodegeneration in experimental models of Parkinson's disease. Sci Transl Med 8(368)ra174\z):368-374. doi.org/10.1126/scitranslmed.aag2210

21. Gu X, Li Y, Chen K, Wang X, Wang Z, Lian H, Lin Y, Rong X (2020) Exosomes derived from umbilical cord mesenchymal stem cells alleviate viral myocarditis through activating AMPK/mTORmediated autophagy flux pathway. Cell Mol Med 24(13):7515-7530. doi.org/10.1111/jcmm.15378

22. Harun MHN, Sepian SN, Chua KH, Ropilah AR, Abd-Ghafar N, Che-Hamzah J, Idrus RBH, Annura FH (2013) Human forniceal region is the stem cell-rich zone of the conjunctival epithelium. Hum Cell 26(1):35-40. doi.org/10.1007/s13577-011-0025-0

23. Hashemi M, Kalalinia F (2015) Application of encapsulation technology in stem cell therapy. Life Sci 143:139-146. doi.org/10.1016/j.Ifs.2015.11.007

24. Jankovic J (2019) Pathogenesis-targeted therapeutic strategies in Parkinson's disease. Mov Disord 34(1):41-44. doi.org/10.1002/mds.27534

25. Jiang J, Jiang J, Zuo U, Gu Z (2013) Rapamycin protects the mitochondria against oxidative stress and apoptosis in a rat model of Parkinson's disease. Int J Mol Med 31(4):825-832. doi.org/10.3892/ijmm.2013.1280

26. Klein AD, Mazzulli JR (2018) Is Parkinson's disease a lysosomal disorder? Brain 141(8):2255-2262. doi.org/10.1093/brain/awy147

27. Lee KY, Mooney DJ (2012) Alginate: properties and biomedical applications. Prog Polym Sci 37(1):106-126. doi.org/10.1016/j.progpolymsci.2011.06.003 
28. Liu L, Jin X, Hu CF, Li R, Zhou Z, Shen CX (2017) Exosomes Derived from Mesenchymal Stem Cells Rescue Myocardial Ischaemia/Reperfusion Injury by Inducing Cardiomyocyte Autophagy Via AMPK and Akt Pathways. Cell Physiol Biochem 43:52-68. doi.org/10.1159/000480317

29. Luk KC, Kehm V, Carroll J, Zhang B, O’Brien P, Trojanowski JQ, Lee VM (2012) PathologicalaSynuclein transmission initiates Parkinson-like neurodegeneration in non-transgenic mice. Science 338(6109):949-953.doi.org/ 10.1126/science.1227157

30. Maiese K, Chong ZZ, Shang YC, Wang S (2013) mTOR: on target for novel therapeutic strategies in the nervous system. Trends Mol Med 19(1):51-60. doi.org/10.1016/j.molmed.2012.11.001

31. Malagelada C, Jin ZH, Jackson-Lewis V, Przedborski S, Greene LA (2010) Rapamycin protects against neuron death in in vitro and in vivo models of Parkinson's disease. Neurosci 30(3):11661175.doi.org 10.1523/JNEUROSCI.3944-09.2010

32. Marei HES, El-Gamal A, Althani A, Afifi N, Abd-Elmaksoud A, Farag A, Cenciarelli C, Thomas C, Anwarul $\mathrm{H}$ (2018) Cholinergic and dopaminergic neuronal differentiation of human adipose tissue derived mesenchymal stem cells. J Cell Physiol 233(2):936-945. doi.org/10.1002/jcp.25937

33. Menzies FM, Fleming A, Rubinsztein DC (2015) Compromised autophagy and neurodegenerative diseases. Nat Rev Neurosci 16:345-357. doi.org/10.1038/nrn3961

34. Messripour M, Ali-Babaie Z (1994) Modulation of dopamine uptake and release in rat striatal synaptosomes by glycine and glutamate. Mol Chem Neuropathol 23(1):1-12. doi.org/10.1007/BF02858503

35. Messripoura M, Gheisaryb MM, Mesripourc M (2018) Age related effects of levodopa on rat brain striatal acetylcholinesterase. Neurochem J 12(1):48-52. doi.org/10.1134/S1819712418010105

36. Moriarty N, Pandit A, Dowd E (2017) Encapsulation of primary dopaminergic neurons in a GDNF loaded collagen hydrogel increases their survival, re-innervation and function after intra-striatal transplantation. Sci Rep 7:16033. doi.org/10.1038/s41598-017-15970-w

37. Mostafavi H, Ghasemifard L, Rostamo A, Alipour A, Nadri S (2019) Trabecular meshwork mesenchymal stem cell transplantation improve motor symptoms of parkinsonian rat model. Biologicals 61:61-67. doi.org/10.1016/j.biologicals.2019.06.006

38. Nadri S, Yazdani S, Arefian E, Gohari Z, Eslaminejad MB, Kazemi B, Soleimani M (2013) Mesenchymal stem cells from trabecular meshwork become photoreceptor-like cells on amniotic membrane. Neurosci Lett 541:43-48. doi.org/10.1016/j.neulet.2012.12.055

39. Nadri S, Soleimani M, Mobarra Z, Amini S (2008a) Expression of dopamine-associated genes on conjunctiva stromal-derived human mesenchymal stem cells. Biochem Biophys Res Commun. 2008a; 377(2), 423-8. doi.org/10.1016/j.bbrc.2008.09.148

40. Nadri S, Soleimani M, Kiani J, Atashi A, Izadpanah R (2008b) Multipotent mesenchymal stem cells from adult human eye con junctiva stromal cells. Differentiation 76(3):223-231. doi.org/10.1111/j.1432-0436.2007.00216.x

41. Nakka VP, Prakash-Babu P, Vemuganti R (2016) Crosstalk between endoplasmic reticulum stress, oxidative stress, and autophagy: Potential therapeutic targets for acute CNS injuries. Mol Neurobiol 
53:532-544. Doi.org/10.1007/s12035-014-9029-6

42. Obeso JA, Stamelou M, Goetz CG, Poewe W, Lang AE, Weintraub D, Burn D, Halliday GM, Bezard E, Przedborski S, Lehericy S, Brooks DJ, Rothwell JC, Hallett M, DeLong MR, Marras M, Tanner CM, Ross GV, Langston JW, Klein C, Bonifati V, Jankovic J, Lozano AM, Deuschl G, Bergman H, Tolosa E, Rodriguez-Violante M, Fahn S, Postuma RB, Berg D, Marek K, Standaert G, Surmeier DJ, Olanow CW, Kordower JH, Calabresi P, Schapira AHV, Stoessl AJ (2017) Past, present, and future of Parkinson's disease: a special essay on the 200th anniversary of the shaking palsy. Mov Disord 32(9):12641310. doi.org/10.1002/mds. 27115

43. Park HJ, Shin JY, Kim HN, Oh SH, Lee PH (2014) Neuroprotective effects of mesenchymal stem cells through autophagy modulation in a parkinsonian model. Neurobiol Aging 35(8):1920-1928. doi.org/10.1016/j.neurobiolaging.2014.01.028

44. Perez RG, Waymire JC, Lin E, Liu JJ, Guo F, Zigmond MJ (2002) A role for alpha-synuclein in the regulation of dopamine biosynthesis. J Neurosci 22:3090-3099

45. Raza C, Anjum R, Shakeel N (2019) Parkinson's disease: mechanisms, translational models and management strategies. Life Sci 226:77-90. doi.org/10.1016/j.Ifs.2019.03.057

46. San-Jose LH, Stephens P, Song B, Barrow D (2018) Microfluidic Encapsulation Supports Stem Cell Viability, Proliferation, and Neuronal Differentiation. Tissue engineering Part C: Methods 24(3):158171. doi.org/10.1089/ten.tec. 2017.0368

47. Santini E, Heiman M, Greengard P, Valjent E, Fisone G (2009) Inhibition of mTOR signaling in Parkinson's disease prevents L-DOPA-induced dyskinesia. Science Signaling 2(80):36. .doi.org/10.1126/scisignal.2000308

48. Sardi SP, Cedarbaum JM, Brundin P (2018) Targeted therapies for Parkinson's disease: from genetics to the clinic. Mov Disord 33(5):684-696. doi.org/10.1002/mds.274

49. Schwerk A, Altschüler J, Roch M, Gossen M, Winter C, Berg J, Kurtz A, steiner B (2015) Human adipose-derived mesenchymal stromal cells increase endogenous neurogenesis in the rat subventricular zone acutely after 6-hydroxydopamine lesioning. Cytotherapy 17(2):199-214. doi.org/10.1016/j.jcyt.2014.09.005

50. Scrivo A, Bourdenx M, Pampliega O, Cuervo AM (2018) Selective autophagy as a potential therapeutic target for neurodegenerative disorders. Lancet Neuro 17(9):802-815. doi.org/10.1016/S1474-4422(18)30238-2

51. Shall G, Menosky M, Decker S, Nethala P, Welchko R, Leveque X, Lu m, Sandstrom M, Hochgeschwender U, Rossignol J, Dunbar G (2018) Effects of passage number and differentiation protocol on the generation of dopaminergic neurons from rat bone marrow-derived mesenchymal stem cells. Int J Mol Sci. 2018; 19(3), 720-50. doi.org/10.3390/ijms19030720

52. Subramaniam S, Napolitano P, Mealar R, Kim S, Errico F, Barrow R,et al (2012) Rhes, a striatalenriched small G protein, mediates mTOR signaling and L-DOPA-induced dyskinesia. Nat Neurosci 15:191-193. doi.org/10.1038/nn.2994 
53. Tan WH, Takeuchi S (2007) Monodisperse alginate hydrogel microbeads for cell encapsulation. Adv Mater 19(18):2696-2701. doi.org/10.1002/adma.200700433

54. Teixeira FG, Carvalho MM, Souza N, Salgado AJ (2013) Mesenchymal stem cells secretome: a new paradigm for central nervous system regeneration? Cell Mol Life Sci 70(20):3871-3882. doi.org/10.1007/s00018-013-1290-8

55. Venkatesh K, Sen D (2017) Mesenchymal stem cells as a source of dopaminergic neurons: a potential cell based therapy for Parkinson's disease. Curr Stem Cell Res Ther 12(4):326-347

56. Vizoso FJ, Eiro N, Cid S, Schneider j, Perez-Fernandez R (2017) Mesenchymal stem cell secretome: toward cell-free therapeutic strategies in regenerative medicine. Int J Mol Sci 18(9):1852-1876. doi.org/10.3390/ijms18091852

57. Wang Y, Ding L, Wang X, Zhang J, Han W, Feng L, Sun J, Jin H, Wang XJ (2012) Pterostilbene simultaneously induces apoptosis, cell cycle arrest and cyto-protective autophagy in breast cancer cells. American Journal of Translational Research 4(1):44-51

58. Wang Y, Yang J, Li H, Wang X, Zhu L, Fan M, Wang X (2013) Hypoxia promotes dopaminergic differentiation of mesenchymal stem cells and shows benefits for transplantation in a rat model of Parkinson's disease. PLoS One 8(1):e54296. Doi.org/10.1371/journal.pone.0054296

59. Wei ZG, Wu RL, Lavker RM, Sun TT (1993) In vitro growth and differentiation of rabbit bulbar, fornix, and palpebral conjunctival epithelia. Implications on conjunctival epithelial transdifferentiation and stem cells. Invest Ophthalmol Vis Sci 34(5):1814-1828

60. Wu K-P, Weinstock DS, Narayanan C, Levy RM, Baum J (2009) Structural reorganization of alphasynuclein at low pH observed by NMR and REMD simulations. J Mol Biol 391(4):784-796. doi.org/10.1016/j.jmb.2009.06.063

61. Yao R, Zhang R, Lin F, Luan J (2012) Injectable cell/hydrogel microspheres induce the formation of fat lobulelike microtissues and vascularized adipose tissue regeneration. Biofabrication 4(2), Article ID045003. doi.org/10.1088/1758-5082/4/4/045003

62. Zhang Y, Ge M, Hao Q, Dong B (2018) Induced pluripotent stem cells in rat models of Parkinson's disease: A systematic review and meta-analysis. Biomed Rep 8(3):289-296. doi.org/10.3892/br.2018.1049

\section{Tables}

Table1. Primer sequence for RT-qPCR. 


\begin{tabular}{|ll|}
\hline Genes & Primer sequences \\
\hline a-Syn & Forward: 5'-GGTTCCAAAACTAAGGAAGG -3' \\
& Reverse: 5'-CCTCCAACATTTGTCACTTG-3' \\
\hline mTOR & Forward: 5'-CGCGAACCTCAGGGCAA-3' \\
& Reverse: 5'-CTGGTTTCCTCATTCCGGCT-3' \\
B-actin & Forward: 5'-GCTCTGGCTCCTAGCACCAT -3' \\
& Reverse: 5'-GCCACCGATCCACACAGAGT-3' \\
\hline
\end{tabular}

\section{Figures}

B
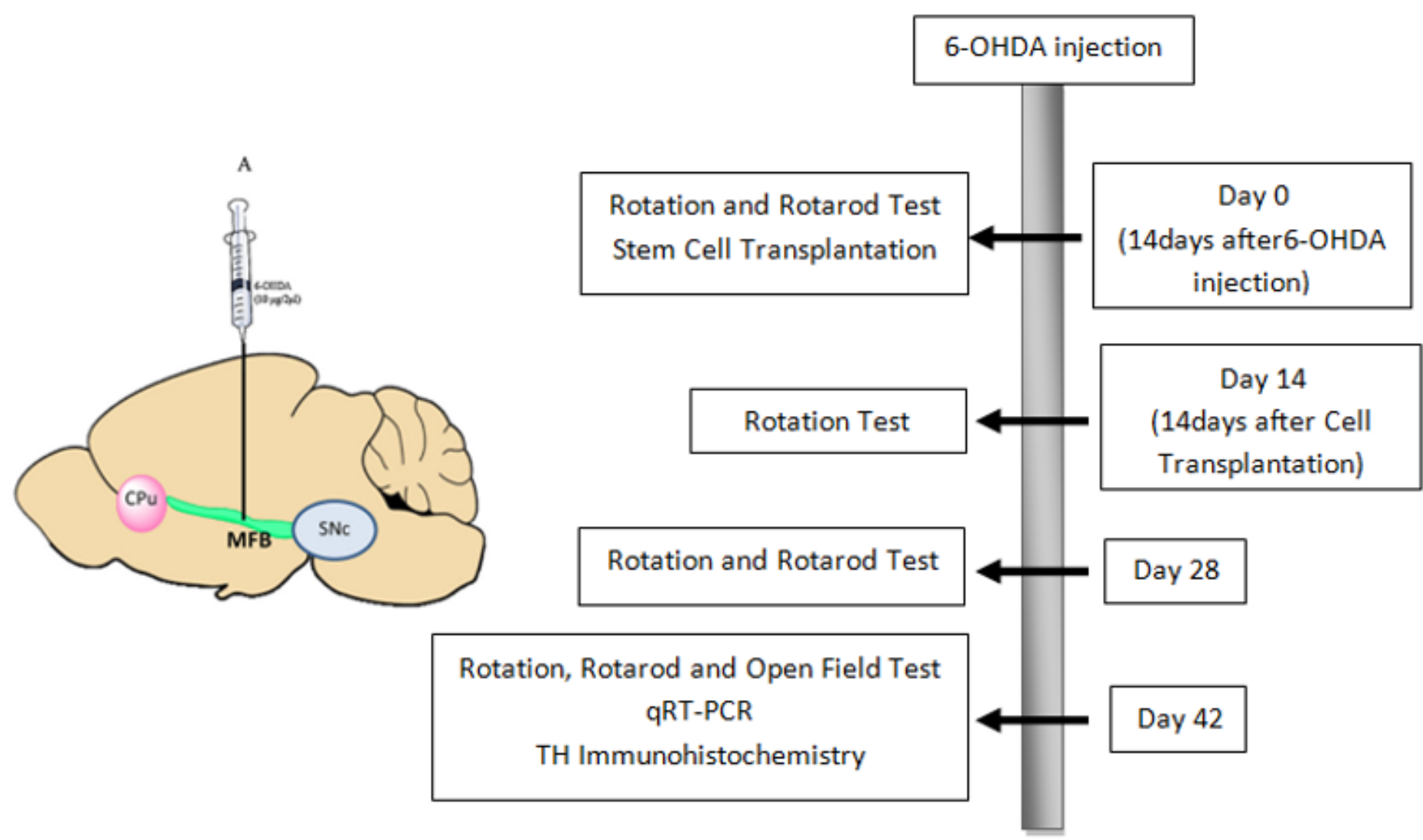

Figure 1

A schematic diagram of the 6-OHDA injection site $(A)$ and timeline schematic diagram of the present study (B) 

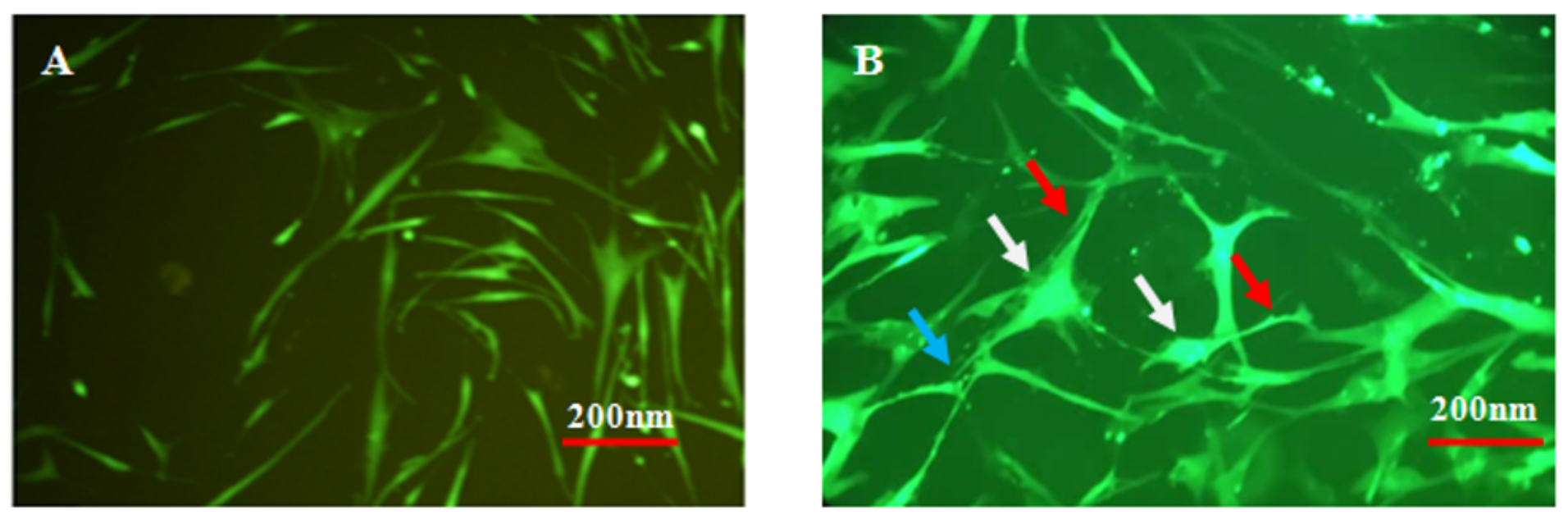

\section{Figure 2}

Human-derived CJ-MSCs from the human eye (A) isolated CJ-MSCs a week after exposure to the induction medium. Pyramidal cell body (white arrows), cell appendages (red arrows), and synaptic-like cell contacts (blue arrow) (B). 
A

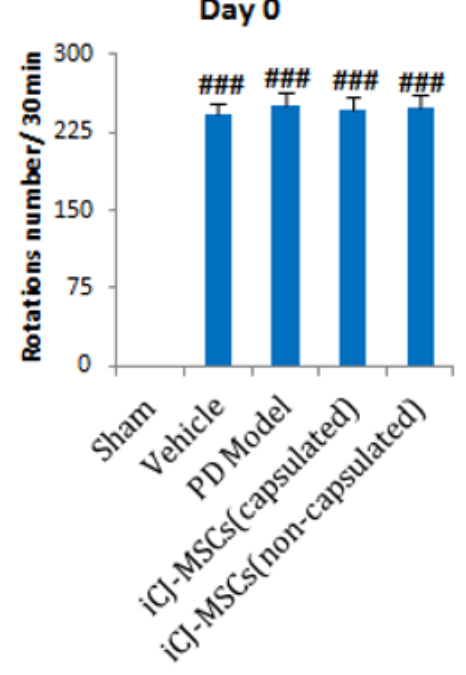

B

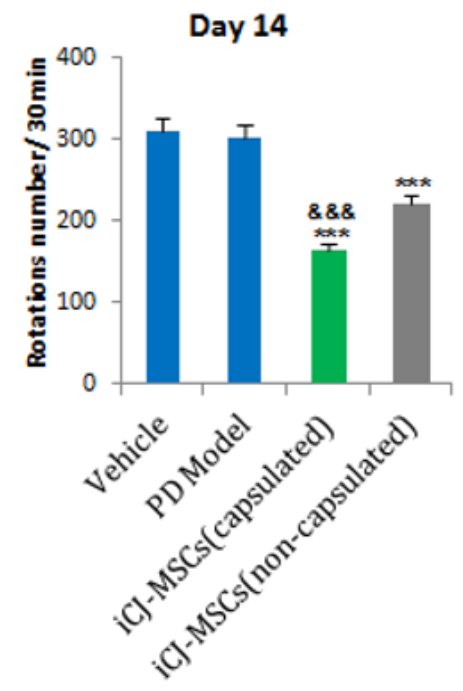

C

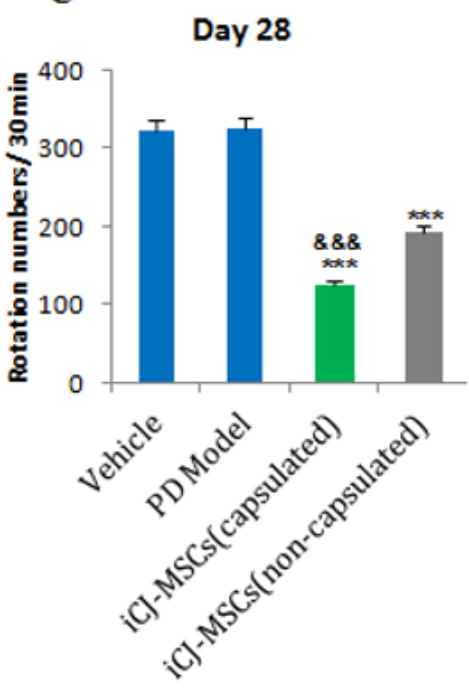

D

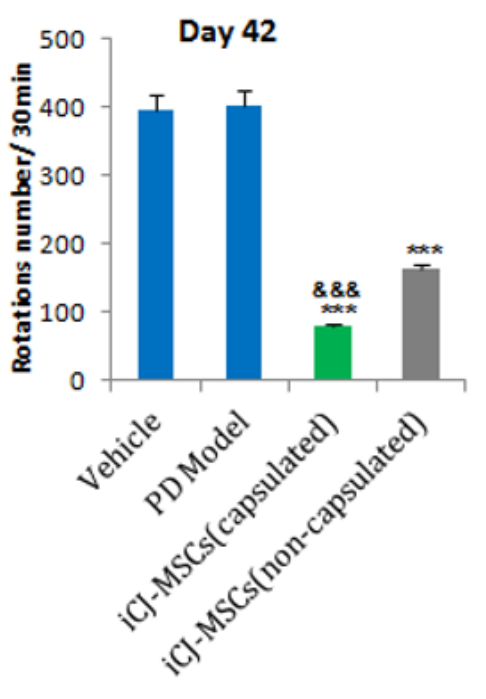

\section{$\mathbf{E}$}

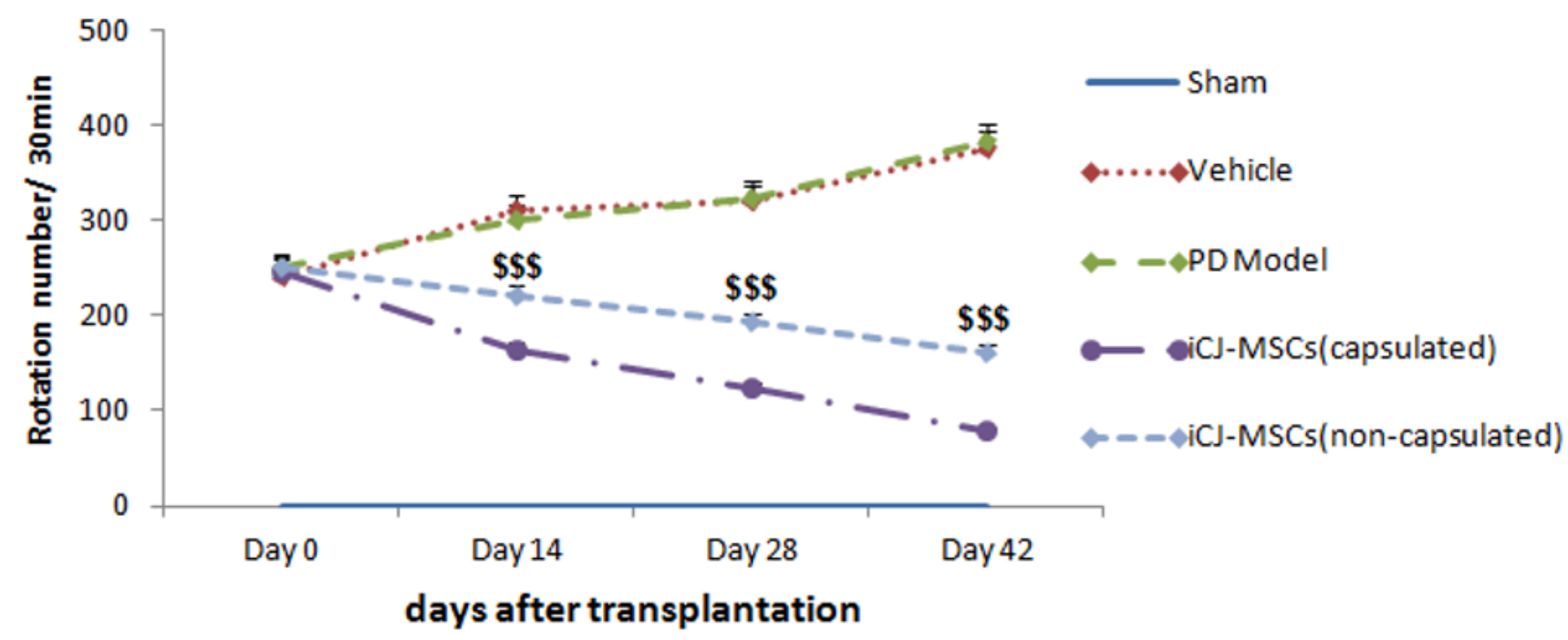

Figure 3

The bar and linear chart for the number of rotations induced by apomorphine in the different groups and days. The data obtained showed that injection of 6-OHDA toxin resulted in apomorphine-induced rotations to the lesion's opposite side (A). Fourteen days after CJ-MSCs transplantation, a significant decrease in the number of rotations was observed in the CJ-MSCs transplanted rats than the model group (B). The data on days 28 and 42 indicated a decreasing trend in the number of rotations (C, D). It was significant in the encapsulated-CJ-MSCs transplanted rats compared to the non-capsulated CJ-MSCs. The number of rotations of the treated groups on day 42 was significantly different from those on days 28,14 , and 0 . There was a significant difference between the number of rotations of day 28 with days 14 and 0 and day 14 with day $0(E)$. \#\#\#P<0.001 vs. sham, ${ }^{\star * \star} P<0.001$ vs. PD model and Vehicle, $\& \& \& P<0.001$ vs. iCJ-MSCs (non-capsulated), $\$ \$ \$ P<0.001$ compared to all weeks of the same treated group. Values include mean \pm standard deviation. $(n=8$ per each group) 

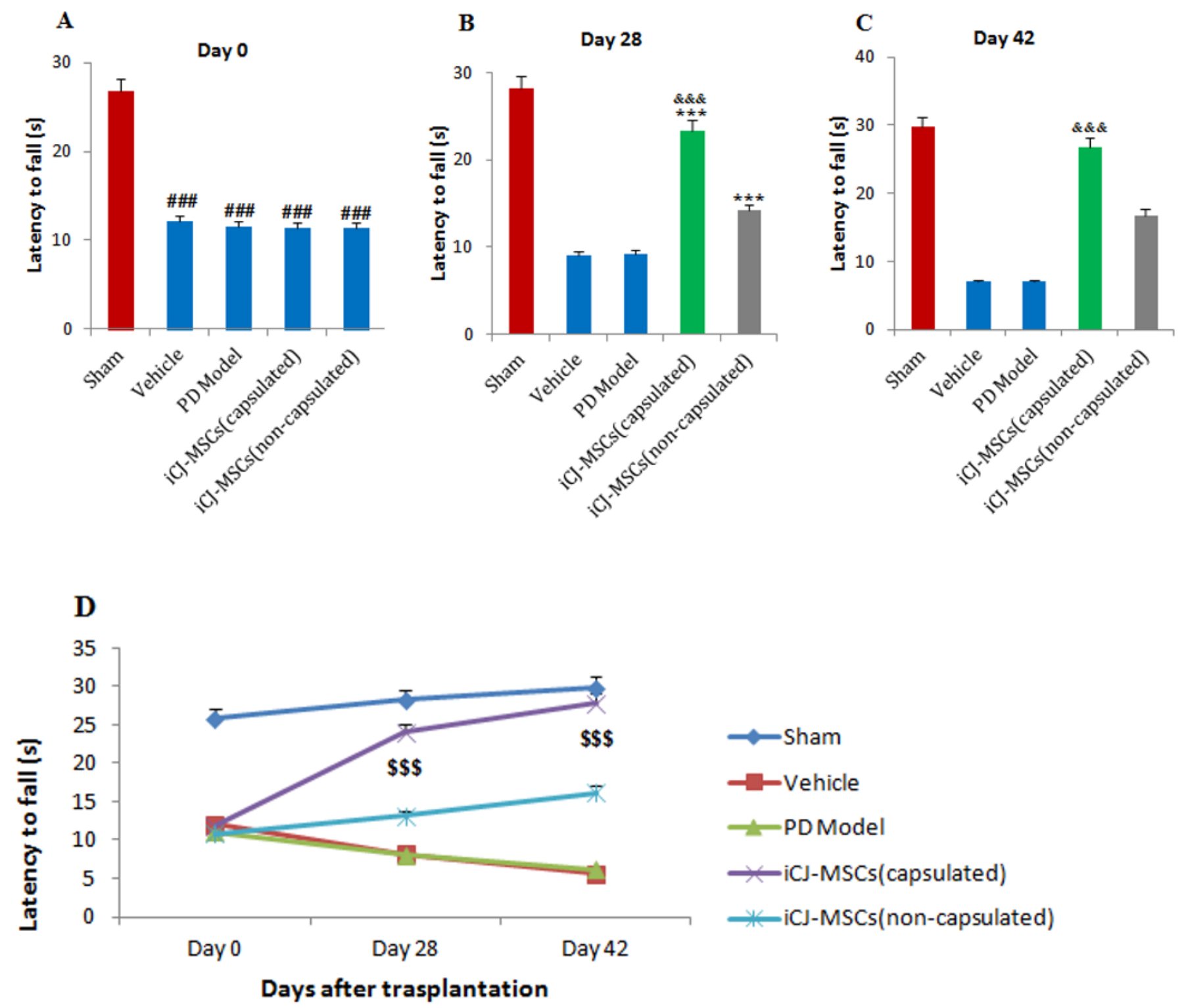

Figure 4

The diagrams of the residence time on the rotating rod. The residence time of rats on the rotating rod following PD induction has been significantly reduced compared to healthy rats (sham group) (A). Treatment of rats with CJ-MSCs transplantation significantly increased the retention time of rats on the rotating rod compared to the model group (B). The rat balance on days 28 and 42 has increased retention time on the rotating rod for CJ-MSCs transplanted rats (C). There was a significant difference in the retention time for CJ-MSCs transplanted groups on day 42 compared to day 28 and zero and on day 28 compared to day zero (D). \#\#\#P<0.001 vs. sham, ${ }^{\star} * \star P<0.001$ vs. $P D$ model and Vehicle, $\& \& \& P<0.001$ vs. iCJ-MSCs (non-capsulated), $\$ \$ \$ P<0.001$ compared to all weeks of the same treated group. Values include mean \pm standard deviation. ( $n=8$ per each group) 

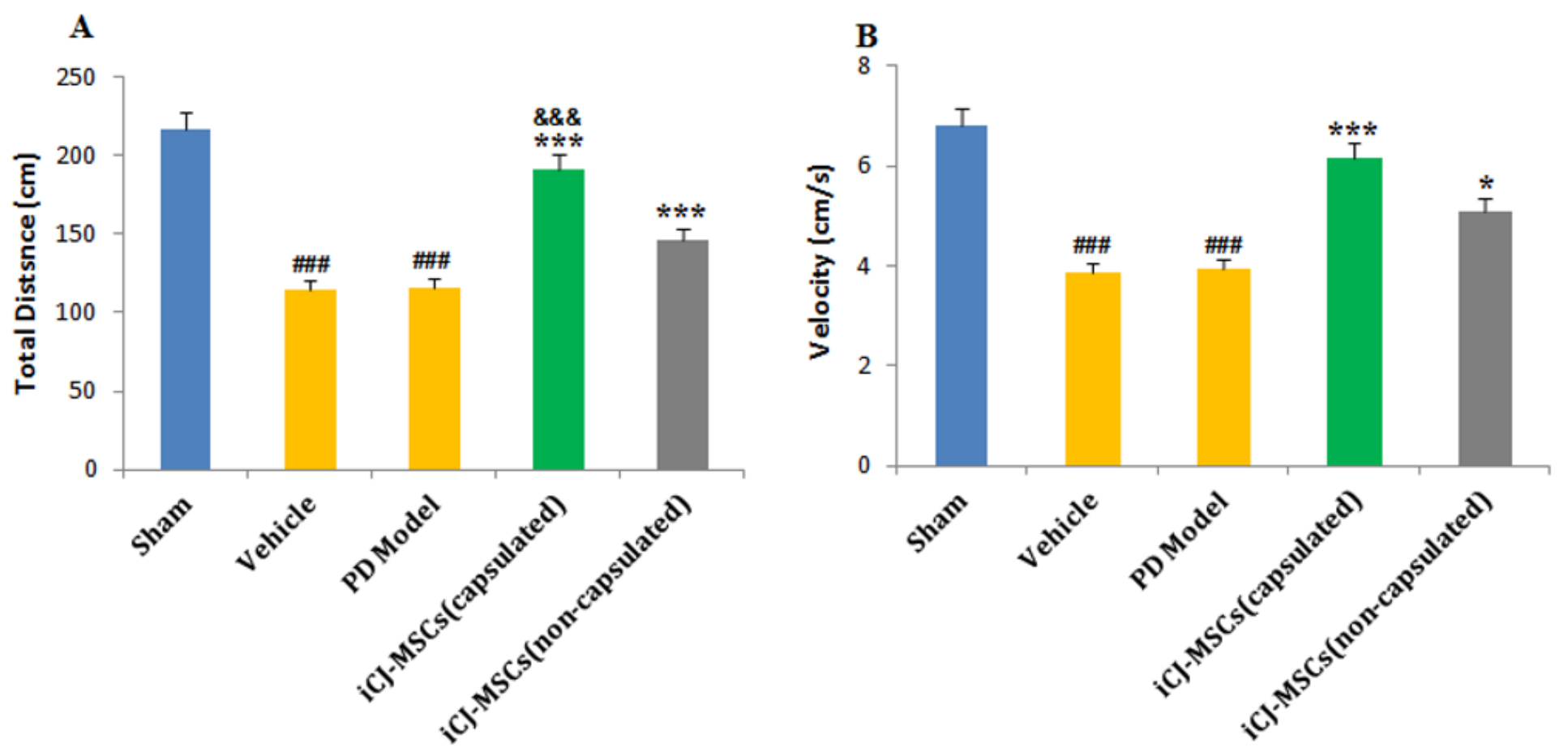

Figure 5

The traveled distance and mean velocity in the study groups. Parkinson's induction decreased total distance (A) and velocity (B) in the PD model groups compared to the sham group. Transplantation of CJMSCs increased the total distance and velocity compared to the PD model group. It was also significantly increased in the encapsulated CJ-MSCs transplanted rats than non-encapsulated CJ-MSCs transplanted rats $(A, B) . \# \# \# P<0.001$ vs. sham, $* \star \star P<0.001$ vs. $P D$ model and Vehicle, ${ }^{*} P<0.1$ vs. $P D$ model, Vehicle and iCJ-MSCs (capsulated), \&\&\&P<0.001 vs. iCJ-MSCs (non-capsulated), $\$ \$ P<0.001$ compared to all weeks of the same treated group. Values include mean \pm standard deviation. $(n=8$ per each group) 
A

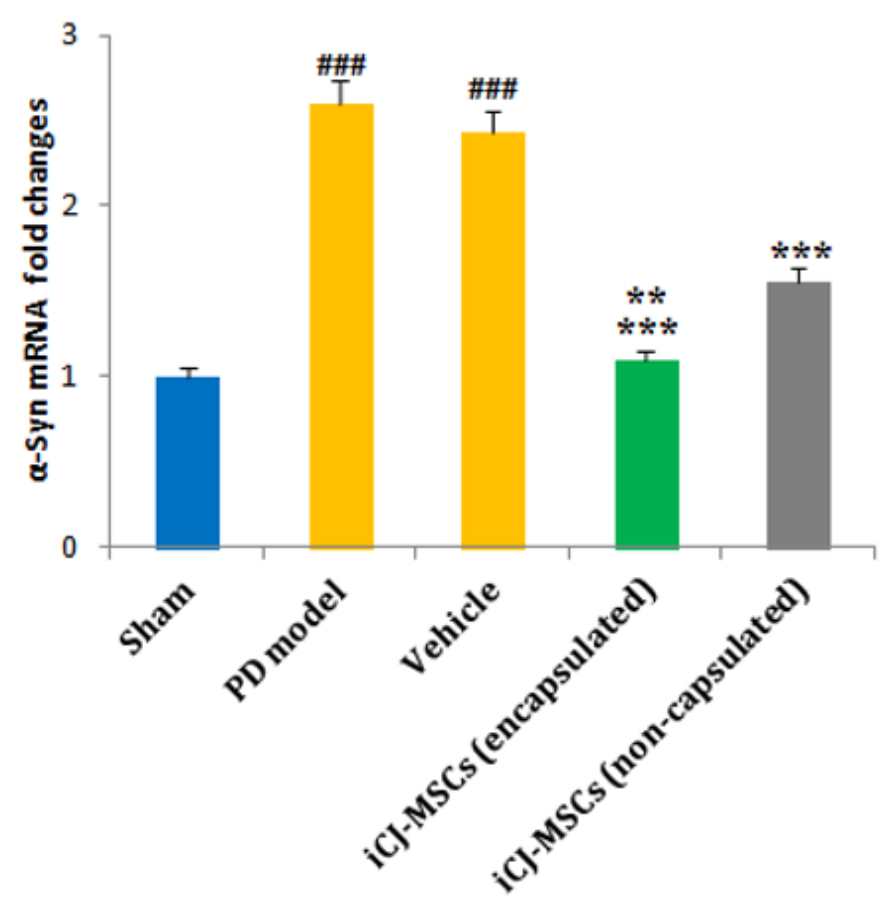

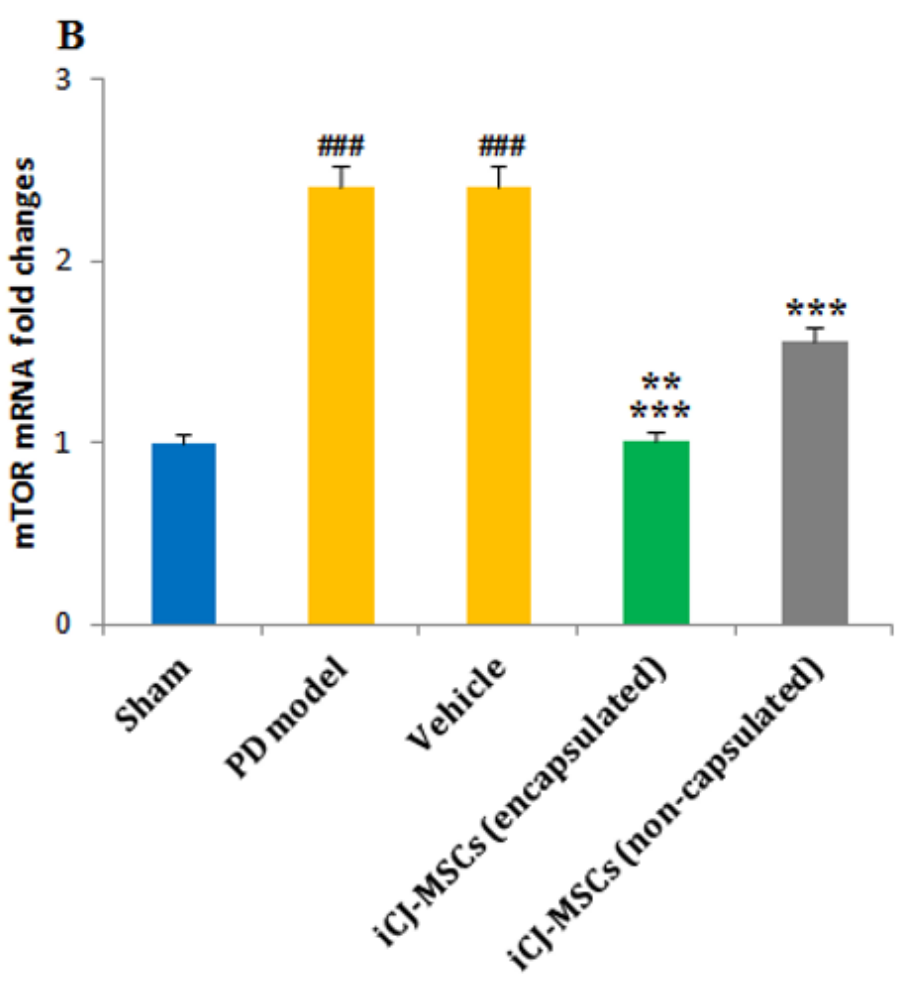

\section{Figure 6}

The changes in a-Syn and mTOR gene levels in different groups. Following induction of Parkinson's, the levels of a-Syn (A) and mTOR(B) were significantly upregulated compared to the sham group. CJ-MSCs transplantation decreased the regulation of a-Syn and mTOR mRNA levels. The reduction was significant in the encapsulated CJ-MSCs transplanted rats than non-encapsulated CJ-MSCs transplanted rats $(A, B)$. $\# \# \# P<0.001$ vs. sham, ${ }^{*} * \mathrm{P}<0.001$ vs. $P D$ model and Vehicle, ${ }^{*}<<0.1$ vs. $P D$ model, Vehicle and iCJ-MSCs (capsulated), ${ }^{\star *} \mathrm{P}<0.01 \mathrm{vs}$. iCJ-MSCs (non-capsulated). Values include mean \pm standard deviation. $(\mathrm{n}=8$ per each group)
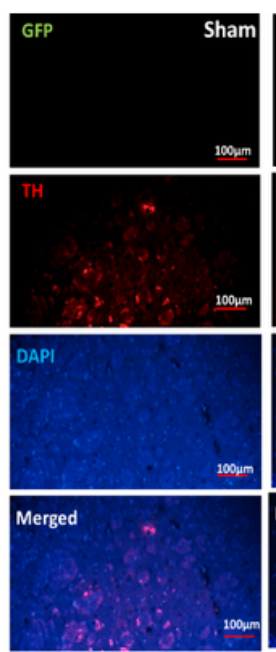
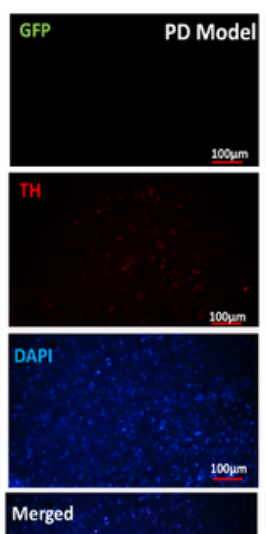
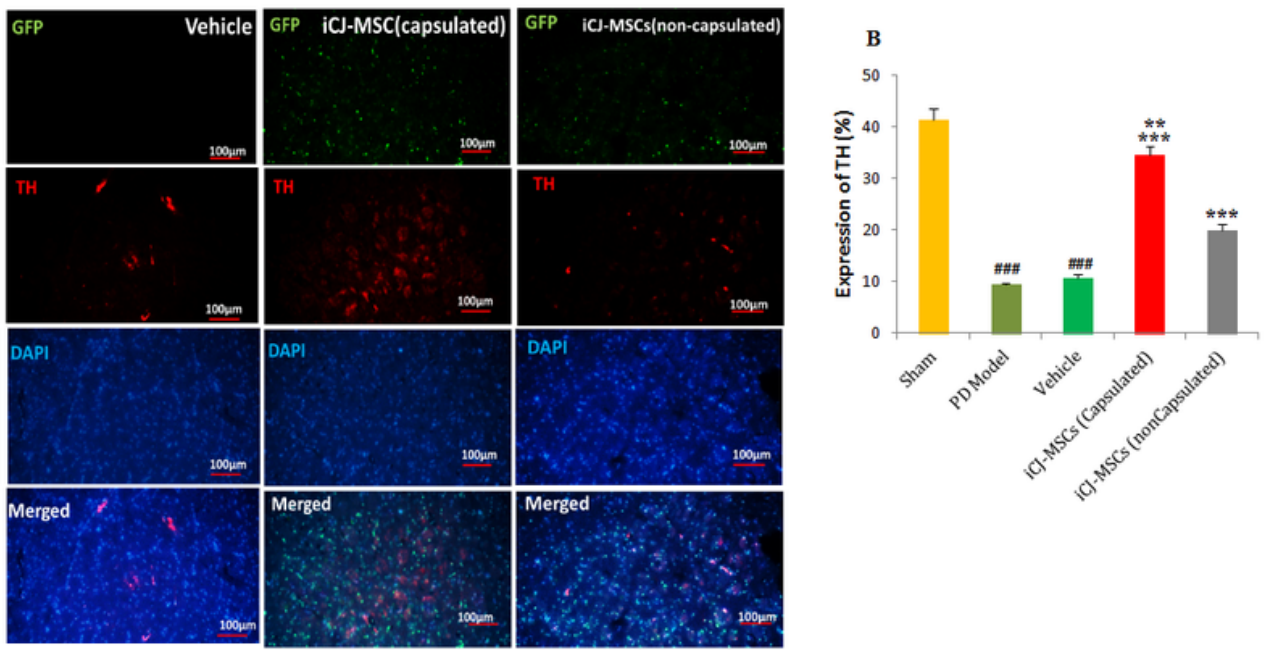

Figure 7 
Immunohistochemical staining of the striatum region to evaluate TH expression in the rats of different groups (A). The TH + cells have been significantly decreased after 6-OHDA injection compared to healthy rats. CJ-MSCs transplantation leads to an increase in the number of $\mathrm{TH}+$ cells in the striatum of rats.

Encapsulated CJ-MSCs caused a significant rise in $\mathrm{TH}+$ cell compared to non-encapsulated transplanted CJ-MSCs (B). \#\#\#P<0.001 vs. sham, ${ }^{* * * P<0.001 ~ v s . ~ P D ~ m o d e l ~ a n d ~ V e h i c l e, ~}{ }^{*} P<0.1$ vs. PD model, Vehicle and iCJ-MSCs (capsulated), $* * P<0.01$ vs. iCJ-MSCs (non-capsulated). Values include mean \pm standard deviation. ( $\mathrm{n}=8$ per each group)

\section{Supplementary Files}

This is a list of supplementary files associated with this preprint. Click to download.

- SupplementryFig1.png

- SupplementryFig2.png 